\title{
Is Pakistan prepared to tackle the coronavirus epidemic?
}

\author{
Muhammad Saqlain $^{1} \cdot$ Muhammad Muddasir Munir $^{2} \cdot$ Ali Ahmed $^{3} \cdot$ Azhar Hussain Tahir $^{1} \cdot$ Sohail Kamran $^{1}$
}

Published online: 20 March 2020

(c) Springer Nature Switzerland AG 2020

The World Health Organization (WHO) has classified the coronavirus epidemic as a global public health emergency of international concern [1]. On 11 February 2020, the virus was named by the WHO as 'severe acute respiratory tract coronavirus-2' (SARS-CoV-2; also referred to as 2019nCOV), and the disease it causes as 'COVID-19' [1].

On 26 February 2020, for the first time, the number of new cases outside China was higher than the number of new cases inside China (427 vs. 411 new cases) [2]. By 11 March 2020, the virus had spread to 113 countries and territories, with the number of registered cases reaching 118,162 and the number of deaths reaching 4290 (mortality rate $3.63 \%$ ) [3]. The WHO states that the COVID-19 outbreak is now categorized as a pandemic, with the number of cases increasing by 13-fold in 2 weeks [4], and has issued alerts to countries at risk of getting COVID-19 [5].

Also on 26 February 2020, the Pakistan Federal Health Minister confirmed the first two cases of COVID-19 in Karachi and Islamabad [2, 6]. Within 15 days (12 March), the total number of positive COVID-19 tests reached 20, with 14 cases in Sindh Province, 5 in Gilgit Baltistan and 1 in a 12-year-old child in Baluchistan) [7]. All cases had a history of a recent visit to Iran, Syria or London. To 12 March 2020,

Ali Ahmed

ali.ahmed@monash.edu

Muhammad Saqlain

msaqlain@bs.qau.edu.pk

Muhammad Muddasir Munir

muddasir.mughal786@gmail.com

Azhar Hussain Tahir

azhartahir313@gmail.com

Sohail Kamran

kamran1978pk@yahoo.com

1 Department of Pharmacy, Quaid-I-Azam University, Islamabad 45320, Pakistan

2 Institute of Pharmaceutical Sciences, University of Veterinary and Animal Sciences, Lahore, Pakistan

3 School of Pharmacy, Monash University, Subang Jaya, Selangor, Malaysia a total of 471 suspected samples had been tested, $20(4.25 \%)$ of which were found to be positive [7].

Pakistan borders countries infected with COVID-19, including China, an epicenter of the disease that currently has the highest number of deaths attributed to COVID-19 $(n=3162)$, to the north, and Iran, a country with the third highest number of COVID-19-associated mortalities $(n=291)$, to the west; Italy has the second highest number of deaths [3]. This geographical location, as well as a continual increase in the number of confirmed cases, demands a high level of preparedness and requires actions to be taken promptly before the situation becomes worse [8]. The WHO states that countries should take steps to prevent and limit further spread of the virus, including active surveillance, early detection, quarantine, clinical management, and tracing of close contacts [5].

After declaration of the COVID-19 epidemic, the Pakistan government took several measures to cope with this zoonotic illness. First, the federal government, in collaboration with the Civil Aviation Authority, established a system to screen every passenger who had traveled directly or indirectly from China and other infected countries, including South Korea, Japan, and Thailand [8]. After the importation of COVID19 from Iran, Pakistan also started closed monitoring and more active screening of passengers travelling from Iran [9]. Media reports highlighted that, although a screening system was established, lapses have been seen in detection, which required a more effective system to be installed [7].

The Pakistani National Institute of Health (NIH) has played a pivotal role in devising and circulating protocols regarding COVID-19 prevention, transmission and defection, as well as launching public awareness campaigns. These relate to the use of personal protective equipment and facemasks, the handling of suspected cases, sample collection and transport through virus transport medium, and adequate hand and general body hygiene, etc. [10]. The federal NIH also provides support to all Pakistani provinces for establishing provincial surveillance units [8].

During the early days of COVID-19, Pakistan lacked any diagnostic facilities, and suspected samples were sent to foreign laboratories. Pakistan later received test kits from China 
and primers from Japan. Currently, Pakistan is capable of testing samples from suspected cases within the country at the main diagnostic laboratory at the NIH [11], and also at WHO-designated COVID-19 test centers in seven hospitals countrywide (two centers each in Karachi and Quetta, and one center each in Peshawar, Islamabad and Lahore) [12].

Only a few specific quarantine centers are currently established in Pakistan. There is a single modern quarantine center with 300 beds in Islamabad [13], and, in Baluchistan, a province that borders Iran, a quarantine center for 2000 people has been prepared, but the center has run out of room and lacks standard screening and protective equipment [14]. Apart from these specific facilities, the government has established isolation wards and quarantine areas in teaching hospitals; however, media reports have highlighted that most of these hospitals violate COVID-19 preparedness guidelines and, despite establishing new standardized isolation areas, isolation nets previously used during dengue fever outbreaks are now being used for COVID-19 patients [15].

Pakistan had enough facemasks to fulfil its local needs; however, due to increased demand and export to China [16], facemasks became scarce in local Pakistani markets, resulting in a sudden increase in prices. To cope with the situation, the National Disaster Management Authority asked the government to ban the export of facemasks and other relevant materials. The drug regulatory authority of Pakistan has also taken actions against illegal stockists and profiteers, and the situation is now under control [16].

Unfortunately, Pakistan is located between two main coronavirus centers, i.e. China and Iran, with considerable traffic to and from these countries. Compared with China and Iran, Pakistan has a lower standard of health care and facilities, and a government that is less strong. Due to its social and political structure, the Pakistani government will not be able to take actions against COVID-19 such as those shown in China and Iran, and can never use the religious references that have been used by the governments of Saudi Arabia and the United Arab Emirates. Therefore, the only way Pakistan can avoid disaster is to have everyone-from the Prime Minister to the ordinary Pakistani-to work together to prevent this outbreak from spreading. Until the danger has been overcome, Muslim scholars continue to mention the COVID-19 outbreak in every Friday sermon, and have also requested that it be mentioned in every prayer.

\section{Take home messages}

- The current coronavirus situation is in check in Pakistan.

- Experts recommend that, given this developing country's history of dealing with other disease outbreaks and its fragile fragmented healthcare system and poor health literacy, the government and all relevant institutes should be on high alert and well prepared to tackle any unusual situation.
Author contributions All authors contributed to the preparation of this commentary.

\section{Compliance with ethical standards}

Funding No funding was received for this commentary.

Conflict of interest None declared.

\section{References}

1. World Health Organization. Coronavirus. https://www.who.int/ health-topics/coronavirus. Accessed 6 Mar 2020.

2. Ali I. Pakistan confirms first two cases of coronavirus, govt says "no need to panic". https://www.dawn.com/news/amp/1536792. Accessed 27 Feb 2020.

3. Novel coronavirus (COVID-19) situation 2020 Mar 11. https:// experience.arcgis.com/experience/685d0ace521648f8a5beeeee1 b9125cd. Accessed 11 Mar 2020.

4. WHO Director-General's opening remarks at the media briefing on COVID-19; 11 March 2020. https://www.who.int/dg/speeches/ detail/who-director-general-s-opening-remarks-at-the-media-brief ing-on-covid-19-11-march-2020. Accessed 11 Mar 2020.

5. COVID-19 strategic preparedness and response plan for the novel coronavirus. https://www.who.int/publications-detail/strat egic-preparedness-and-response-plan-for-the-new-coronavirus. Accessed 6 Mar 2020.

6. Pakistan latest victim of coronavirus. https://www.geo.tv/lates t/274482-pakistan-confirms-first. Accessed 7 Mar 2020.

7. COVID-19 live dashboard (Pakistan): National Institute of Health Islamabad. https://www.nih.org.pk/covid-2019-live-dashboardf/. Accessed 12 Mar 2020.

8. Controlling coronavirus. https://www.thenews.com.pk/tns/ amp/606911-controlling-coronavirus. Accessed 27 Feb 2020.

9. Pakistan 'concerned' over Iran coronavirus outbreak, closes border. https://www.geo.tv/latest/273964-pakistan-alert. Accessed 6 Mar 2020.

10. COVID-19-National Institute of Health Islamabad. https://www. nih.org.pk/novel-coranavirus-2019-ncov/. Accessed 6 Mar 2020.

11. Pakistan now equipped to test for novel coronavirus, says PM's aide. https://www.dawn.com/news/1532077. Accessed 6 Mar 2020.

12. These are the $7 \mathrm{WHO}$ designated coronavirus test centers in Pakistan. https://propakistani.pk/2020/02/28/these-are-the-7who-designated-coronavirus-test-centers-in-pakistan/. Accessed 6 Mar 2020.

13. Coronavirus quarantine center with 300 beds established in Islamabad. https://92newshd.tv/coronavirus-quarantine-center-with300-beds-established-in-islamabad/\#.XmKa0KgzbIU. Accessed 6 Mar 2020.

14. Coronavirus quarantine centre at Pak-Iran border runs out of space. https://www.samaa.tv/news/pakistan/2020/03/coron avirus-quarantine-centre-at-pak-iran-border-runs-out-of-space/. Accessed 6 Mar 2020.

15. Total chaos: hospitals in Pak lack facilities to treat corona patients. https://dailytimes.com.pk/566099/total-chaos-hospitals-in-paklack-facilities-to-treat-corona-patients/. Accessed 7 Mar 2020.

16. Govt warns stern actions against traders who raise face mask price: Nausheen Hamid. https://dailytimes.com.pk/567976/govtwarns-stern-actions-against-traders-who-raise-face-mask-price -nausheen-hamid/. Accessed 7 Mar 2020. 